\title{
Research on Combustion Chamber Structure Improvement and Ignition System of Missile Turbojet Engine for Diesel Fuel
}

\author{
Lei QIU, Xi ZENG, Shiming JI, Fengfei XI, Wenbin QIU, Qianqian ZHENG
}

\begin{abstract}
To meet the conditions of diesel ignition, this paper presents several structural improvements of a small missile turbojet engine for diesel fuel. The engine starts motor-assisted, and its fuel is ignited by silicon nitride ceramic ignitor. Theoretical analysis is performed by establishing a mathematical model of the combustion model and combustion conditions. The feasibility of diesel used as a small turbojet fuel is analyzed by using numerical simulation software. Research is carried out based on the following points: the improvement of combustion chamber and evaporator, selection of ignitor position and sustainability of fire. This paper proposed the method of linking the engine-assisting startup system and selected the right type of ignitor, and on the advanced experimental platform several groups ignition tests were carried out
\end{abstract}

Keywords: combustion chamber; diesel; ignition system; missile; turbojet

\section{INTRODUCTION}

The performance of turbojet is based on several key factors, in which most important are continuous fuel supplying and rapidly reliable ignition. These key factors can make the turbojet start rapidly and fuel burn reliably, thus the turbojet will go to the idle rating state. It is very significant to study the fuel and ignition modes of turbojet, especially for small turbojet which works in a state of low thrust and long distance cruise.

Following methods are some usual ways which are used in the normal ignition of small missile turbojet, such as wind milling starting, powder starting, and compressed air starting. If wind milling method is taken as an instance, high-speed airflow drives the rotor to start engine before fuel supply system supplying continuous fuel $[1,2]$. Since this starting method requires the engine rotating in a high speed, this method is generally used in the circumstances in which the turbojets are lunched by booster, or carried by aircraft directly. In other word, this method is proper for the state when turbojets are in high speed. Therefore, the application of this method is not wide enough. As for the powder starting method, ignition completes by the powder ignitor installed in the micro nozzle, which can produce high temperature and high pressure gas to drive the turbine blade. At present, powder starting method is the most reliable and rapid starting method of micro turbojet. However, the powder ignitor is one-off luxury product and it is hard to recovery or maintain, which is not a choice for acting on the idea of sustainable development [3]. Compressed air starting method uses compressed air produced by low-pressure air compressor to push engine compressor blades to drive the engine rotor run. This starting method is usually used in ground test. Although the compressed air provides adequate air for ignition [4], the ignition power is much lower than the powder ignition providing, which leads to a much longer start-up. Obviously, it is not suitable for occasions where ignition has to be completed instantly.

Different starting-ignition methods have different requirements for fuel. The stringent demand for fuel and the series of problems caused by the fuel demand have become the obstacle in popularizing and applying a small turbojet, especially for the application of military filled such as missile turbojet. In this paper, the starting and ignition method of a small missile turbojet for diesel fuel is studied, and a new ignition method is proposed, which combines the large power high speed motor and the silicon nitride ceramic ignitor.

\section{MOTOR-ASSISTED IGNITION SYSTEM}

The rapid development of integrated circuits and small high-speed motors has made it possible for motors to start turbojet engines. This starting method uses the motor to drive the engine rotor and stabilize at a certain speed. The starting motor connects the engine rotor by the clutch, and once the rotor gets the given speed both of them will be separated. Due to the military application background of these small turbojet engines, the related public reports are extremely rare.

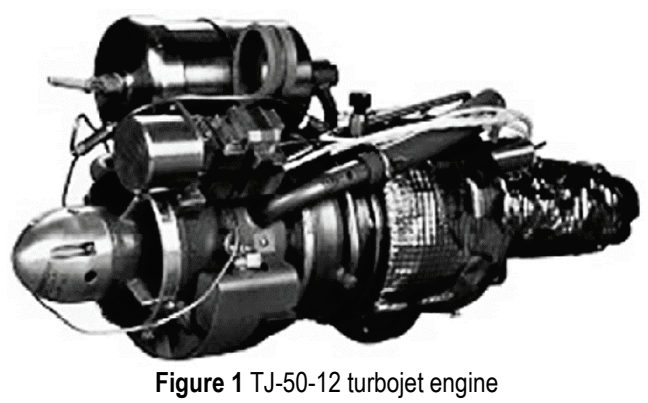

According to a small amount of information disclosed at present, the TJ-50-12 engine used by the US LOCCAS missile [5] and the TJ-30 engine mounted by the LAM loitering missile [6-7] both use motor-assisted ignition system, thus they can be launched in the air. The TJ-50-12 engine and the LAM loitering missile are shown in Fig. 1 and Fig. 2.

The shafting lubrication system of a turbojet engine is often designed as oil mist lubrication. The lubricity of diesel fuel is higher than that of aviation kerosene $[8,9]$. Compared with aviation kerosene, diesel fuel has the characteristics of low price, less affected by lubricating oil and stable combustion. However, its evaporation, atomization, carbon deposition are not as good as aviation kerosene's. The ignition system of diesel engine fueled with diesel fuel should also be improved and adjusted 
accordingly. The basic performance required in the fuel injection engine is shown in Tab. 1 [10-12].

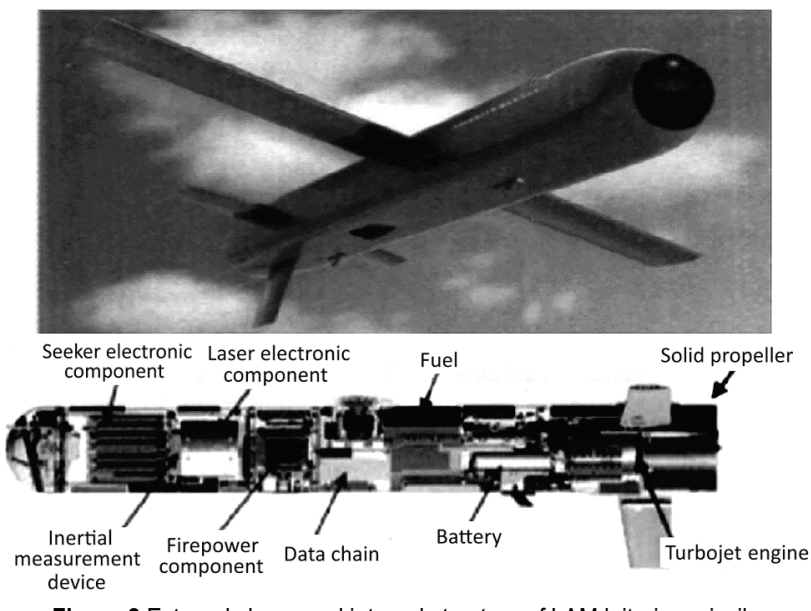

Figure 2 External shape and internal structure of LAM loitering missile

Table 1 The basic performance of turbine engine fuel

\begin{tabular}{|c|c|c|c|c|}
\hline $\begin{array}{c}20{ }^{\circ} \mathrm{C} \\
\text { Density } \\
\left(\mathrm{kg} / \mathrm{m}^{3}\right)\end{array}$ & $\begin{array}{c}\text { Net calorific } \\
\text { value (MJ } / \mathrm{kg})\end{array}$ & $\begin{array}{c}\text { Smoke } \\
\text { point }(\mathrm{mm})\end{array}$ & $\begin{array}{c}\text { Naphthalene } \\
\text { aromatics (\%) }\end{array}$ & $\begin{array}{c}\text { Glow } \\
\text { value }\end{array}$ \\
\hline $775-830$ & 42.8 & 25 & 3.0 & 45 \\
\hline
\end{tabular}

In order to improve the performance of the No. 0 diesel and to make it closer to the above requirements, additives can be added to the fuel. This paper uses several groups of additives to improve the ignition and combustion performance of diesel fuel.

According to the characteristics of diesel fuel, some researchers proposed a way to ignite diesel fuel by using propane ignition, which makes the ignition system more complex rather than conducive to the engine miniaturization and lightweight. The diesel engine can be directly supplied with diesel oil to start ignition, and the fuel switching section and the series of devices generated there may be omitted. From the ignition conditions, it is important to redesign the combustion chamber, the evaporator and select the location of ignitor accurately.

\subsection{Ignition Conditions}

When the engine starts fire, the local high temperature of ignitor causes the surrounding fuel to burn and changes the temperature distribution in the combustion chamber. Then the flame fills the combustion chamber, causing the combustion chamber temperature to exceed the original temperature of the ignitor itself, thus to form a sustained fire $[13,14]$.

It is generally believed that the minimum ignition energy can be expressed as follows:

$\ln \left(\frac{E_{\min } Y_{\mathrm{ox}}^{3 / 2}}{T_{\mathrm{m}}-T_{0}}\right)=\ln A+2 \ln T_{0}-2 \ln \rho+\frac{2}{3} \frac{E}{R T_{\mathrm{m}}}$,

Among them: $A=\frac{4 k_{1} \pi \lambda}{C k_{0}} \sqrt{\frac{3 \lambda}{C k_{0} c_{\mathrm{v}}}}$,

$c_{\mathrm{v}}=\frac{Q}{T_{\mathrm{m}}-T_{0}}$, where: $Q$ is quantity of heat change, $T_{\mathrm{m}}$ is the temperature of the ignitor, $T_{0}$ is the temperature of the surrounding combustibles, $Y_{\text {ox }}$ is distribution of oxygen components, $\rho$ is the density of the fuel gas, $R$ is the constant of the molar gas, $E$ is heat value, $\pi$ is circumference ratio, $\lambda$ is thermal conductivity of fuel gases, $k_{0}, k_{1}$ are constants of reaction rate, $\mathrm{C}$ is the molar concentration of the fuel.

In addition, Lefebvre proposed a more accurate formula of lean oil ignition, which can be used as the following empirical formula:

$q_{\mathrm{LLO}}=\left(\frac{B f_{\mathrm{pz}}}{V_{\mathrm{pz}}}\right)\left(\frac{\dot{m}_{\mathrm{a}}}{p_{3}^{1.5} \exp \left(T_{3} / 300\right)}\right)\left(\frac{D_{\mathrm{o}}^{2}}{\lambda_{\mathrm{eff}} H_{\mathrm{u}}}\right)$,

here, $B$ is determined by the shape of the combustion zone and needs to be selected respectively [15].

$\lambda_{\text {eff }}=\left(\frac{8}{\rho_{\mathrm{f}}}\right)\left(\frac{k_{\mathrm{g}}}{c_{\mathrm{pg}}}\right) \ln (1+B)\left(1+0.22 R e_{D_{\mathrm{o}}}^{0.5}\right.$,

where $R e_{D \mathrm{o}}$ is sauter average diameter equivalent to Reynolds number, $\rho_{\mathrm{f}}$ is the density of the fuel, $k_{\mathrm{g}}$ is the adiabatic constant of the gas, $c_{\mathrm{pg}}$ is heat capacity of constant pressure gas, $T_{3}$ is the temperature at the inlet of the combustion chamber, $\mathrm{p}_{3}$ is static pressure at the entrance of the combustion chamber, $\dot{m}_{\mathrm{a}}$ is the flow of the jet hole, $f_{\mathrm{pz}}$ is the distribution of airflow in the main combustion zone, $V_{\mathrm{PZ}}$ is the volume of the main combustion zone, $D_{\mathrm{o}}$ is sauter average diameter, $H_{\mathrm{u}}$ is the enthalpy of unburned gas.

From the above theory, it can be seen that increasing the inlet pressure of the combustion chamber and the material concentration can make ignition easier. From the fuel point of view, ignition is affected by the fuel performance around the ignitor, and the liquid fuel requires additional energy to evaporate its particles. Obviously, the gas fuel is easier to be ignited comparing to the liquid fuel. Furthermore, maintaining the proper airflow temperature and velocity also makes ignition easier.

\subsection{Combustion Model}

The combustion process of diesel fuel can be regarded as turbulent diffusion combustion [16]. As mentioned above, the flame needs enough energy exchange to stabilize and spread easily [17]. The mixture ratio equation of the diesel vapor and air mixture is expressed as follows:

$$
R=\frac{m_{1}}{m_{1}+m_{2}}
$$

here, the variable $m_{1}$ is the mass of the diesel steam flow, and the variable $m_{2}$ is the mass of the air flow.

In condition of the same molecular diffusion rate of the diesel steam and the air, the transfer equation of the mixing ratio can be expressed by the following form:

$\rho \frac{\partial R}{\partial t}+\rho V \frac{\partial R}{\partial w}=\frac{\partial\left(\rho D_{\mathrm{R}} \frac{\partial R}{\partial w}\right)}{\partial w}$ 
where: $t$ is time (it was a coordinate system), $V$ is velocity, $D_{\mathrm{R}}$ is molecular diffusion coefficient for air combustion mixture in a certain direction, $P$ is air-fuel mixture density.

In the Eq. (6), the two boundary conditions of the air fuel mixture ratio are: (1) the diesel vapor in the evaporator is $100 \%$, (2) the diesel vapor in the air flow is 0 . The combustion chamber evaporation tube near the flame shape can be shown as Fig. 4. In this figure, we can see turbulent flame boundary with irregular shape, $R_{\mathrm{wt}}$ represents flame surface diesel vapor fraction, $x$ represents normal direction at a boundary point of coordinate $w, y$ and $z$ represents tangential direction at a boundary point of the coordinate $w$, thus, the coordinate of flame boundary can be conversed by using partial differential equation chain rule, which is:

$$
\left\{\begin{array}{l}
\frac{\partial}{\partial t}=\frac{\partial}{\partial \tau}+\frac{\partial R}{\partial t} \frac{\partial}{\partial R} \\
\frac{\partial}{\partial x}=\frac{\partial R}{\partial x} \frac{\partial}{\partial R} \\
\frac{\partial}{\partial y}=\frac{\partial R}{\partial y} \frac{\partial}{\partial R}+\frac{\partial}{\partial R_{y}} \\
\frac{\partial}{\partial z}=\frac{\partial R}{\partial z} \frac{\partial}{\partial R}+\frac{\partial}{\partial R_{z}}
\end{array}\right.
$$

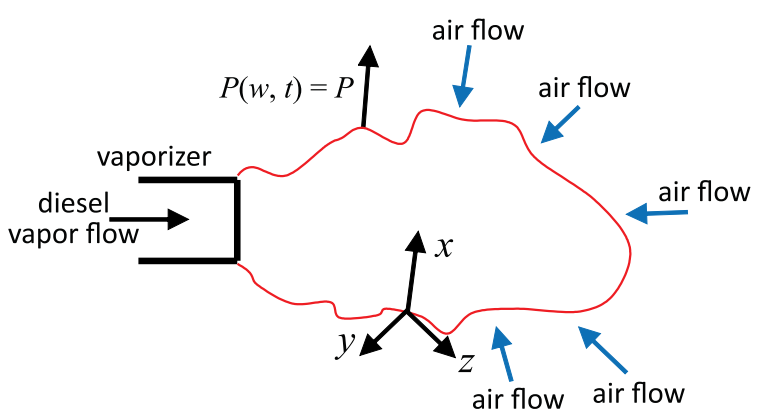

Figure 3 Turbulent flame boundary with irregular shape

The transfer equation of the composition $F_{i}$ and temperature $T$ can be obtained by using the transformation of the Eq. (7):

$$
\begin{aligned}
& \rho \frac{\partial F_{i}}{\partial \tau}+\frac{1}{4}\left(1-\frac{1}{L e_{i}}\right) \frac{\partial(\rho \lambda)}{\partial R} \frac{\partial F_{i}}{\partial w}=\rho \frac{\gamma}{2 L e_{i}} \frac{\partial^{2} F_{i}}{\partial R^{2}}+m_{i}^{\mathrm{o}} \\
& \rho \frac{\partial T}{\partial \tau}-\sum \rho \frac{\gamma}{2 c_{i}} \frac{\partial c_{i}}{\partial R} \frac{\partial T}{\partial R}=\rho \frac{\gamma}{2} \frac{\partial^{2} T_{i}}{\partial R^{2}}+\sum \rho \frac{\gamma}{2 L e_{i}} \frac{\partial c_{i}}{\partial R} \frac{\partial T}{\partial R}- \\
& -\sum \frac{1}{c i} h_{i} m_{i}^{\mathrm{o}}+\sum \frac{1}{c_{i}} \frac{\partial p}{\partial T}+\sum \frac{1}{c i_{i}} q_{\mathrm{R}}^{\mathrm{o}}
\end{aligned}
$$

where $L e_{i}$ is Lewis constant, $c_{i}$ is the heat capacity of the composition $i, h_{i}$ is enthalpy of composition $i, p$ is pressure, $m_{i}^{\mathrm{o}}$ is mass decay, $q_{\mathrm{R}}^{\mathrm{o}} \mathrm{s}$ heat loss for radiation, $\gamma$ is diffusion coefficient.

In this combustion model, combustion occurs and propagates according to the mixture ratio $R$. If the relevant parameters such as the pressure, enthalpy and heat capacity of the material are given, the diesel combustion process can be simulated based on the mixture ratio fraction equation.

The above theory can be used as the theoretical basis for further research.

\subsection{Improvements in Combustion Chambers}

Due to the limitation of structure, small-scale turbojet engine is impossible to use conventional atomizing device such as fuel atomizer, but atomizes and vaporizes fuel by means of an evaporating tube. Temperature plays an important role in fuel atomization and evaporation [18]; selecting an ignitor to preheat the combustion chamber can improve the atomization efficiency of fuel. Therefore, improving the flow velocity distribution of the fuel flow field in the combustion chamber by modifying combustion chamber and evaporating tube can also improve the ignition performance.

Fig. 4 is a combustion chamber structure of an aviation kerosene fuel micro turbojet engine. The end wall of the combustion chamber head is flat, and the evaporating pipe is straight. This short-ring combustion chamber design, with a small aspect ratio, is relatively suitable for new aviation fuels (Such as Number GB6537-94fuel). It is a more economical and practical design to ensure ignition and stable combustion. However, it is not suitable for diesel fuel.

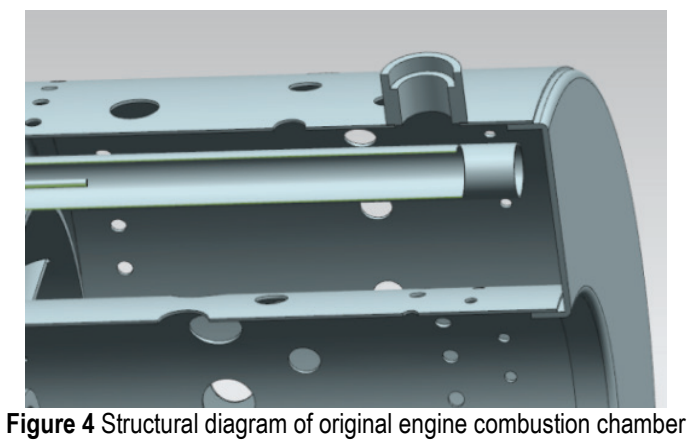

In this paper, we have made two improvements. As shown in Fig. 5, change the flat end wall into an arc end wall to increase the combustion chamber space, so its ability to accommodate high-speed mixing area is increased. Another one is to change outlet of evaporating pipe into bell shape, in order to reduce the fuel vapor flow rate, and to change the direction of the fuel vapor flow.

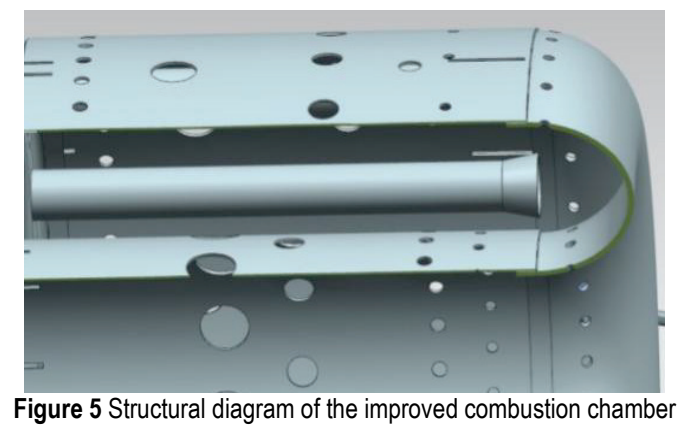

\subsection{The Location of the Ignitor}

The position of the ignitor has a great influence on the ignition. In general, the ignitor of a small turbojet engine is located at the end of the evaporating pipe. Previous researchers believe that the closer the ignitor to fuel vapors, the higher the reliability of ignition. As shown in Fig. 4, this location of the ignitor is just location mentioned above, but the actual results are often unsatisfactory. 
When it comes to a small turbojet engine with diesel fuel, it is difficult to achieve ignition immediately even after the combustion chamber and the vaporizer have been improved if the ignitor placed here, or the engine is barely able to approach ignition but takes too long time. It may waste much more power than needed and even exhaust the battery in the end.

In this paper, it is considered that not only the concentration of fuel gas is large, but also the mixture flow velocity is faster than turbulent flame propagation, which makes ignition difficult near the outlet of the evaporating tube. Although the head of the combustion chamber walls forms a protected area opposite wind, but the wire of ignitor cannot resist high temperature, otherwise the wire of ignitor will cause interference to chamber combustion flow field, thus it is very difficult to install it in this position.

In this paper, Fluent software is used to simulate the oil field and cold flow field at a certain rotational speed (about $10000 \mathrm{rpd} / \mathrm{m}$ ). In order to simplify the calculation, the flow field in the casing of the combustion chamber is taken into account but neglects other insignificant factors, and only $1 / 4$ combustion chambers are selected for calculation, as shown in Fig. 6. The flow field contains two vaporizers, including one static turbine blade, one dynamic turbine blade, one tail nozzle, and one central vertebral body. The three-dimensional model of the flow field is shown in Fig. 7.

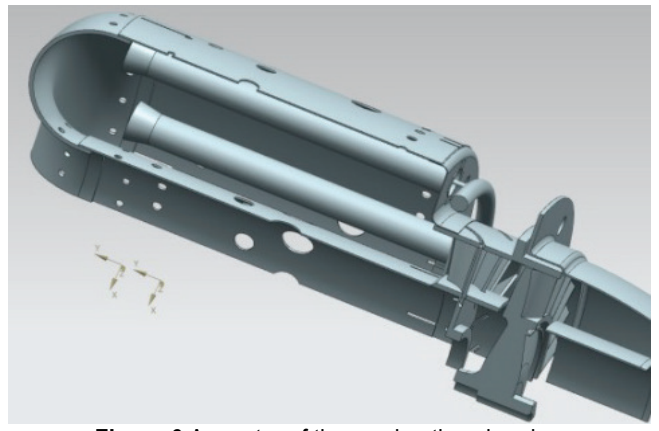

Figure 6 A quarter of the combustion chamber

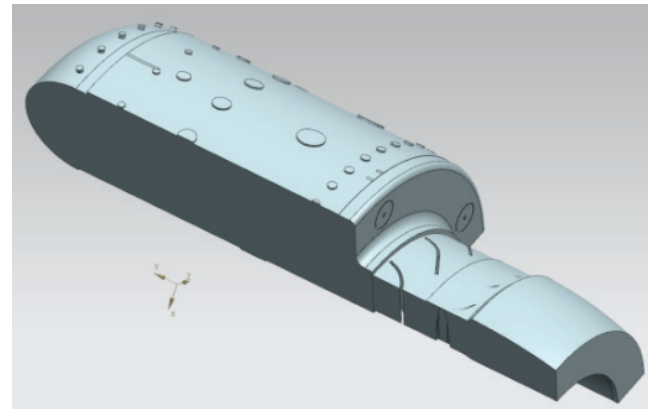

Figure 7 A quarter of the combustion chamber of the internal flow field

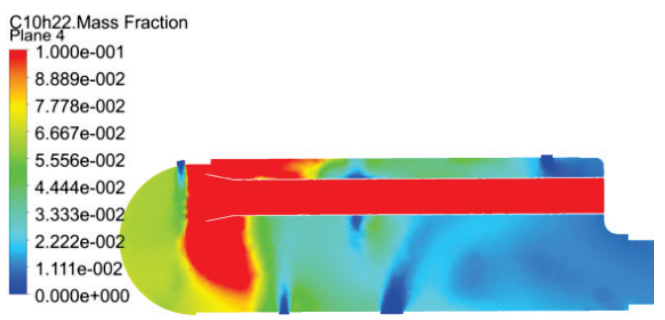

Figure 8 A section of diesel vapor mass fraction

Several sections were selected from the calculated results for analysis. Fig. 8 shows the mass fraction cloud chart of the diesel steam in the circumferential section of the combustion chamber through vaporizer. The mass fraction of diesel vapor at the outlet of the vaporizer reaches 0.1 , while the exit of the combustor decreases to 0.011. Fig. 9 is an oxygen mass fraction of cross section. It is clear that the oxygen mass fraction of the entire section is balanced well at about 0.2 .

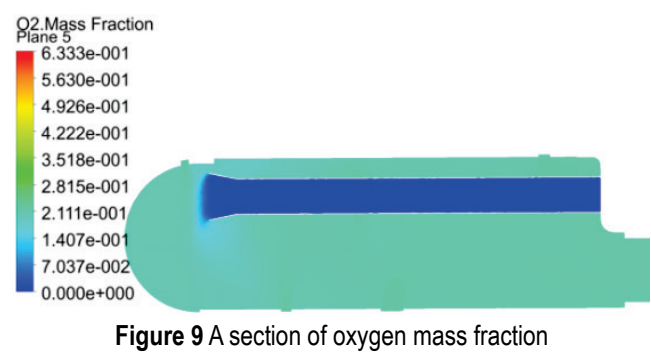

Fig. 10 shows the mass fraction cloud chart of diesel vapor in the middle section of two vaporizers. The diesel vapor mass fraction situation is similar to that shown in Fig. 8. However, near the inner casing, the diesel mass fraction is less compared to Fig. 8. Fig. 11 shows the oxygen mass fraction of the section. The air distribution is very uniform because the air inlet is relatively more outside outer casing of the combustion chamber. The mass fraction of oxygen in the combustion chamber is about 0.2 .

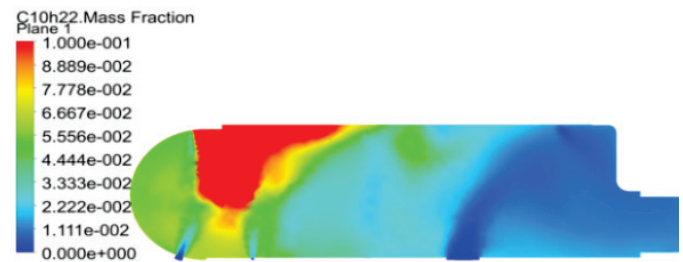

Figure $10 \mathrm{~A}$ section of diesel steam mass fraction

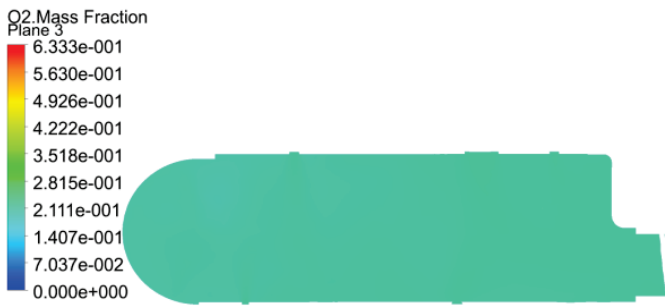

Figure $11 \mathrm{~A}$ section of oxygen mass fraction

Fig. 12 shows the flow rate of the mixed gas in the intermediate section. It can be seen that the flow velocity in the axial middle of the section is uniform and the flow rate is between 10 and $15 \mathrm{~m} / \mathrm{s}$, which is lower than the turbulent flame propagation.

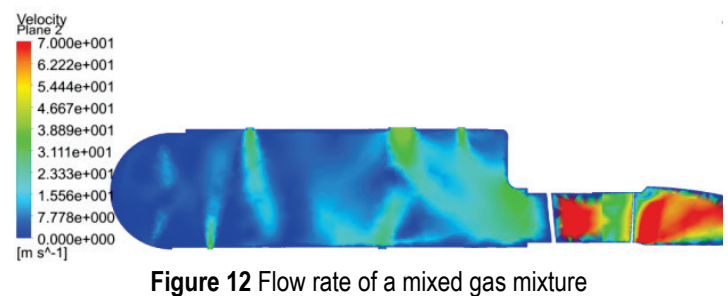

If $\mathrm{C}_{10} \mathrm{H}_{22}$ is taken as the diesel molecular formula for combustion calculation, it is possible to improve the 
reliability of ignition by selecting an appropriate region with reasonable air-fuel ratio and low flow velocity. To sum up, the simulation results show that the location of the ignitor should be in such a region that the circumferential direction is between the two vaporizers and the axial direction is in the middle of the combustion chamber.

According to Arrhenius's empirical formula, the Arrhenius activation energy of diesel steam in this area is smaller at the same temperature:

$$
K=A \mathrm{e}^{-E a / R T}
$$

where $K$ is constant of action, $E a$ is activation energy of Arrhenius, $A$ is pre-exponential factor, $R$ is the constant of the molar gas, and $T$ is thermodynamic temperature.

In the same pre-exponential factor and temperature environment, the reaction rate constant increases due to smaller activation energy in the region, which leads to easier combustion of diesel fuel and oxygen.

\section{SUSTAINABLE IGNITION}

When the ignition operation is completed, the combustion must be sustained without ignitors producing high temperature required for combustion. Turbulence flames will be propagated in the combustion chamber and have to be spread throughout the combustion chamber to produce energy flow to the turbine, which drives the rotor to rotate at high speed.

By using fluent combustion simulation, we can get the temperature distribution in combustion chamber at an instant when combustion is steady. This paper selects several cross sections and longitudinal sections form simulation results. Fig. 13 is a temperature distribution of the circumferential cross section through the fuel tube. It can be seen that the highest temperature is not located at the outlet of vaporizer. The axial cross section at the outlet of vaporizer shown in Fig. 14 also shows this situation.

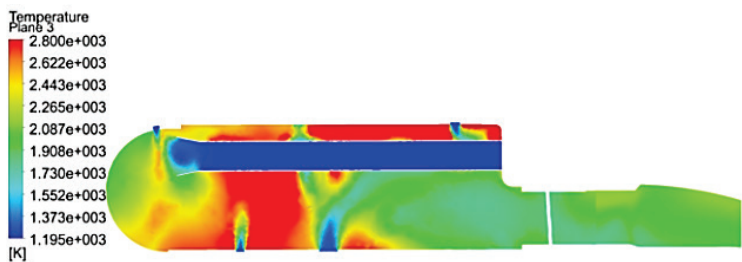

Figure 13 Temperature distribution of circumferential section of fuel pipe

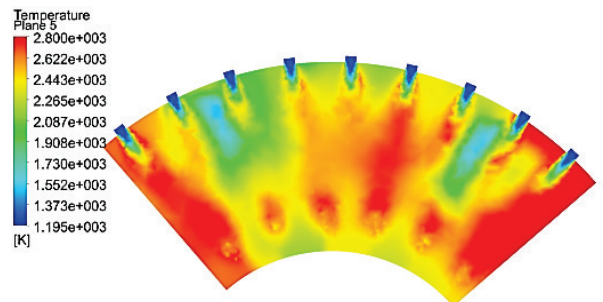

Figure 14 Temperature distribution at the circumferential section of a fuel pipe outlet

Fig. 15 is a circumferential temperature distribution cloud chart between the two vaporizer's middle section, and the highest temperature region is in the middle of the combustion chamber. From the axial cross-section, as shown in Fig. 16, the highest temperature basically fills the entire cross section. As mentioned earlier, an ignitor is installed in this area in this research.

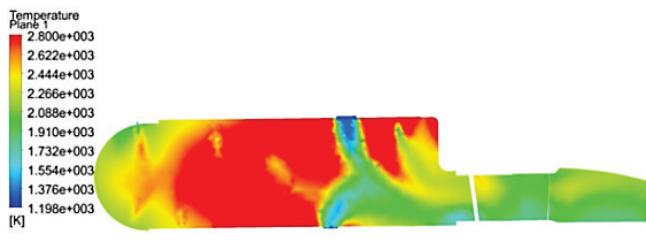

Figure 15 Temperature distribution of a circumferential section

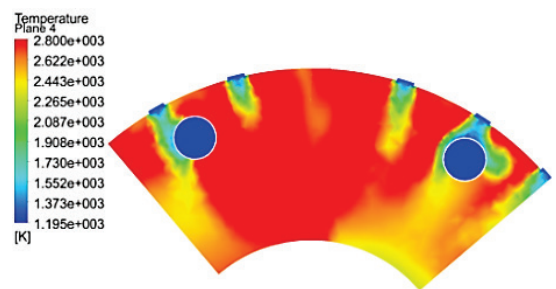

Figure 16 Temperature distribution of an axial section

The simulation results show that the combustion after ignition can keep the rotor rotating about $62 \mathrm{rad} / \mathrm{s}$, which equals to $23362 \mathrm{rpd} / \mathrm{m}$ idling rating. The flow rate of the combustion chamber and the tail nozzle at this time are shown in Fig. 17. It can be seen that after the ignition of the slow state, high speed flow after combustion lashes against the stator turbine blades accompanied by air velocity increasing, then the flow rushes into the dynamic turbine blades with driving the rotor rotation. As we can see, velocity of flow leaving stator decreases, however it increases again when in the tail nozzle. The flow velocity at the end of the tail jet is about $90 \mathrm{~m} / \mathrm{s}$.

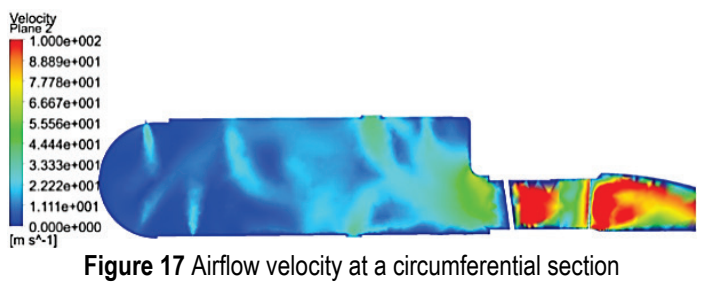

\section{STARTING MOTOR AND IGNITOR 4.1 High Speed Motors and Clutches}

In order for the engine to make a reliable ignition, it is necessary to ensure that its rotor has been driven to selfsteady speed and that the inlet airflow of the compressor is in the ignition envelope [19]. In this paper, a clutch applicable for small turbojet engine is used to connect the starter motor to engine rotor. When the starting motor rotates faster than the engine rotor, the ring outside the clutch extends forward due to the characteristics of the cylindrical cam. When the extending ring touches the compressor lock nut of the engine rotor and goes on until pressing tightly, the engine rotor is driven steadily. The contact between the clutch and the engine rotor is not the simple contact, the clutch and engine rotator are connected by conical surface rather than plain surface, which can remarkably increase the starting torque of the clutch.

Because the engine rotor bearing is made from ceramic matrix composites, the rotor damping is small, and the clutch torque is enough to overcome the friction resistance and the internal resistance of the compressor shaft. After the ignition, the engine's idle speed is still 
higher than the starting speed of the motor so the clutch outside ring draws back due to motion characteristics of cylindrical cam and the clutch and rotor are separated in the end. Fig. 18 is a diagram of the connection between the engine rotor and the starting motor.

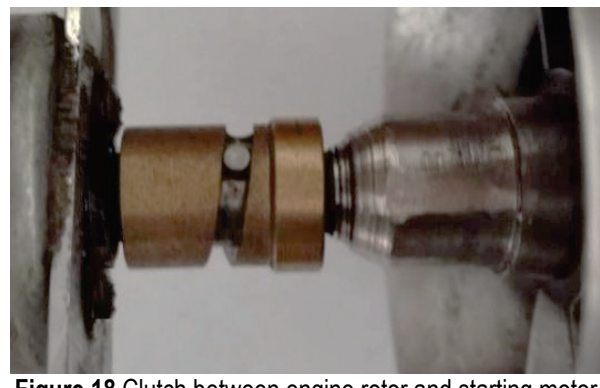

Figure 18 Clutch between engine rotor and starting motor

The small battery and the DC motor are selected to integrate the starter motor with the turbojet engine. In this paper, the maximum speed of high speed motor can reach $19000 \mathrm{rpm}$, and its performance parameters are shown in Tab. 2.

\begin{tabular}{|c|c|c|c|c|c|}
\multicolumn{1}{|c}{ Table 2 Performance parameters of starter motor } \\
\begin{tabular}{|c|c|c|c|c|}
\hline Current \\
$(\mathrm{A})$
\end{tabular} & $\begin{array}{c}\text { Effectiveness } \\
(\%)\end{array}$ & $\begin{array}{c}\text { Output } \\
\text { power } \\
(\mathrm{W})\end{array}$ & $\begin{array}{c}\text { Rotating } \\
\text { speed } \\
(\mathrm{rpm})\end{array}$ & $\begin{array}{c}\text { Torque } \\
(\mathrm{Nm})\end{array}$ \\
\hline $\begin{array}{c}\text { No-load } \\
\text { state }\end{array}$ & 7 & - & - & 19000 & - \\
\hline $\begin{array}{c}\text { Stalling } \\
\text { state }\end{array}$ & 157 & - & - & - & 1470 \\
\hline $\begin{array}{c}\text { Maximum } \\
\text { efficiency }\end{array}$ & 33 & 70 & 413 & 15500 & 255 \\
\hline $\begin{array}{c}\text { Maximum } \\
\text { power }\end{array}$ & 82 & 48 & 721 & 10000 & 735 \\
\hline
\end{tabular}

\subsection{The Choice of Ignitor}

The ignition device studied in this paper has the ability to produce high temperature continuously. The device should not only guarantee high enough ignition temperature of the mixture of diesel steam and air, but also ensure that the diesel vapor particles flowing out of the evaporating pipe are small enough. The ceramic silicon nitride ignitor used in this paper is usually used in the ignition of high speed diesel engines and petroleum media. The ignitor has the advantages of small size, light weight, which can be inserted into the inner wall of the combustion chamber, and without occupying a larger space; high temperature stability and destruction in the combustion region is not broken; fast heating, low temperature start up performance is good and can guarantee the reliable ignition in cold environment. The silicon nitride matrix has good oxidation resistance and is convenient for long-term storage.

In order to demonstrate the advantages of the silicon nitride ceramic ignitor, this paper makes a brief comparison betwen metal ignitor and spark plug. The specific data are shown in Tab. 3.

Table 3 Performance comparison of different kinds of ignitors

\begin{tabular}{|c|c|c|c|c|c|}
\hline & $\begin{array}{c}\text { Ignition } \\
\text { temperature } \\
\left({ }^{\circ} \mathrm{C}\right)\end{array}$ & $\begin{array}{c}\text { Preheating } \\
\text { time }(\mathrm{s})\end{array}$ & $\begin{array}{c}\text { Duration } \\
(\mathrm{s})\end{array}$ & $\begin{array}{c}\text { Repeated } \\
\text { times }\end{array}$ & $\begin{array}{c}\text { Cryogenic } \\
\text { property } \\
\left({ }^{\circ} \mathrm{C}\right)\end{array}$ \\
\hline $\begin{array}{c}\text { Silicon } \\
\text { nitride } \\
\text { ceramics }\end{array}$ & $1200-1300$ & $<10$ & $>120$ & 20000 & -40 \\
\hline $\begin{array}{c}\text { Metal } \\
\text { type } \\
\text { ignitor }\end{array}$ & $800-900$ & $20-40$ & $>60$ & 200 & -5 \\
\hline $\begin{array}{c}\text { Spark } \\
\text { plug }\end{array}$ & $500-950$ & - & 0.001 & - & -20 \\
\hline
\end{tabular}

Fig. 19 is a physical diagram of the ignitor installation. As the engine shell and the combustion chamber wall both are thin-walled parts, which cannot be easily welded, so this article uses screws to fix these two parts. The assembly relationship of the engine casing and the combustion chamber is concentric circle, and the ignitor needs to go deep into the outer casing of the combustion chamber, so the length of the ignitor should not be too long to cause assembly difficulties.

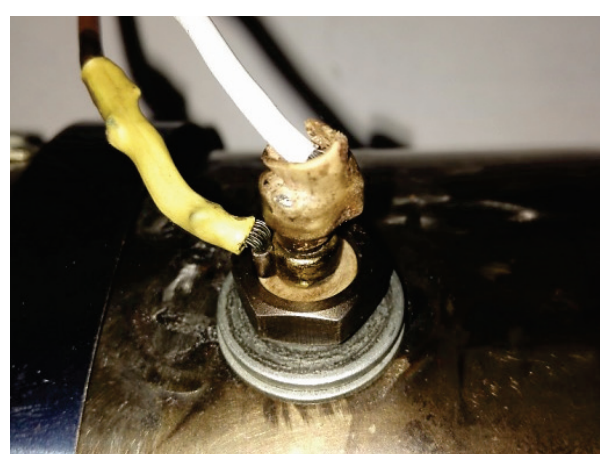

Figure 19 The installation of the ignition diagram

\section{EXPERIMENT}

The experiment was carried out in the laboratory as shown in Fig. 20, As we can see, engine test thrust stand and control room are separated from explosion-proof glass, the whole system adopts more advanced data acquisition equipment, and can realize the on-line monitoring of data.

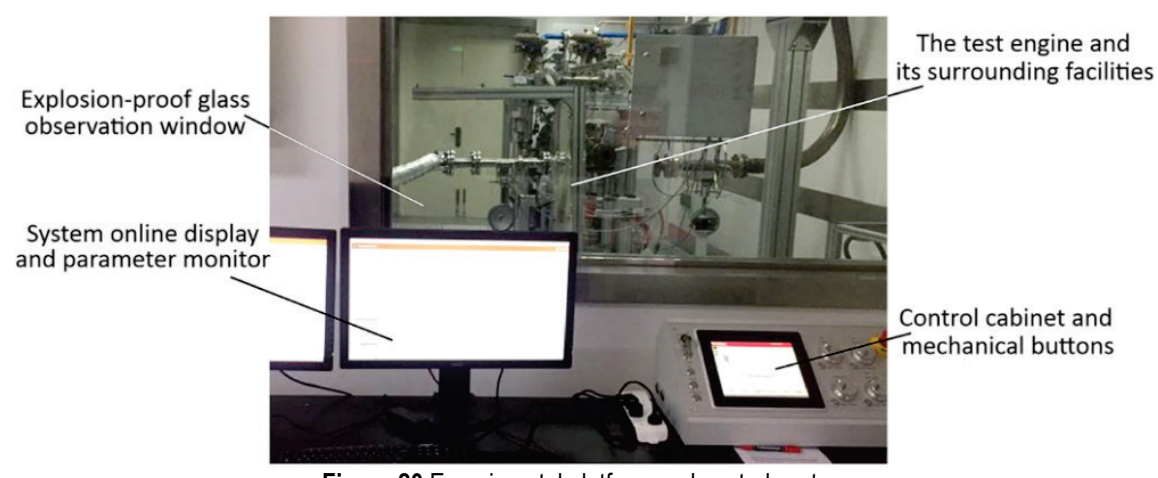

Figure 20 Experimental platform and control system 
Due to the experimental conditions and the cost limits, the tests of this study were carried out on the same engine and the same test platform. However, the engine has been fully cooled before starting the following test. Before ignition, the oil supply circuit has been cleaned by using No. 90 gasoline and dried, to eliminate the effect of the residual fuel in the previous test.
The connection mode of various equipment and sensors on the engine test thrust stand is shown in Fig. 21. It can be seen from the diagram that there are three controllable factors affecting the ignition performance: the starting motor speed, the ignitor temperature and the fuel pump supply.

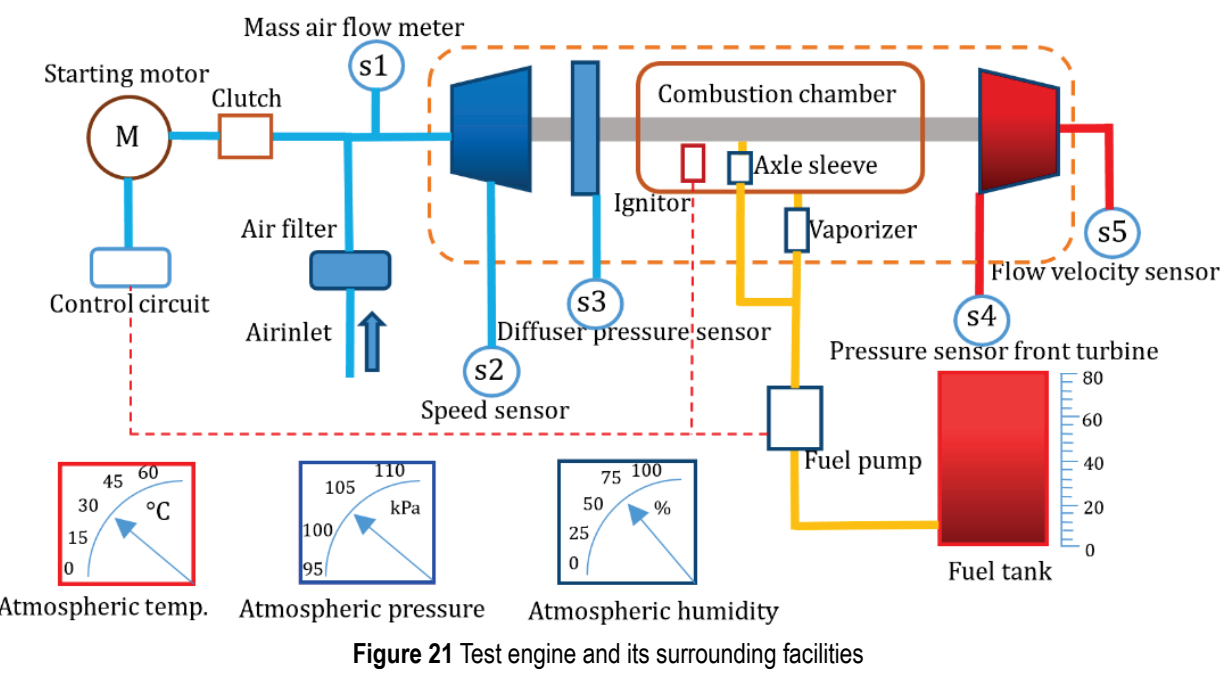

As mentioned earlier, the ignitor has a preheating function for the whole system, which requires the ignitor temperature should be in the highest state. We set the ignitor temperature of 1200 degrees, which is a constant value.

The controllable factors affecting the ignition performance become only two factors: the starting motor speed, and the fuel pump supply. It should be pointed out here, the starting time consuming in the following figure refers to the period between starting fuel pump and complete ignition; before starting fuel pump the ignitor must be fully preheated

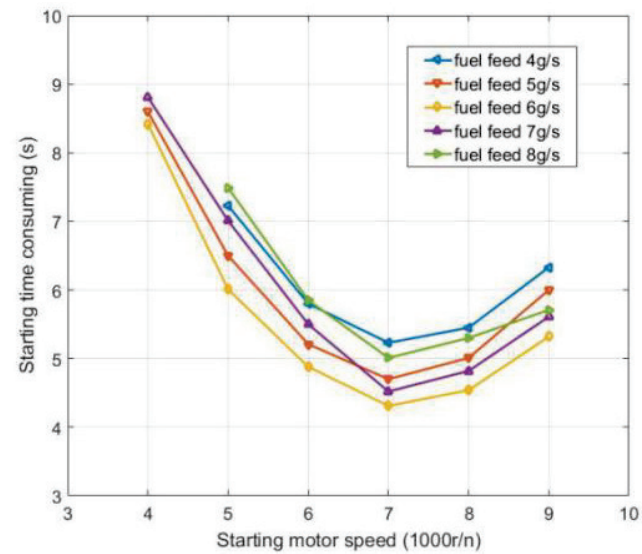

Figure 22 Starting motor speed and starting time consuming relation curve under different fuel supply conditions

Fig. 22 shows the relationship between starting motor speed and starting time consuming under different fuel supply. As we can see, the lowest starting time consuming is $4.31 \mathrm{~s}$ when starting motor speed was $7000 \mathrm{r} / \mathrm{n}$ and fuel supply was 6 g/s. Fig. 22 shows the relationship between starting time and rotor speed under different fuel supply conditions at $7000 \mathrm{r} / \mathrm{n}$ starting motor speed; the rotor speed increases with the increase of fuel supply after successful ignition. However, the ignition time does not have such a rule. The minimum value of starting time consuming appears when the fuel supply is $6 \mathrm{~g} / \mathrm{s}$. As the fuel supply increases, the ignition time increases.

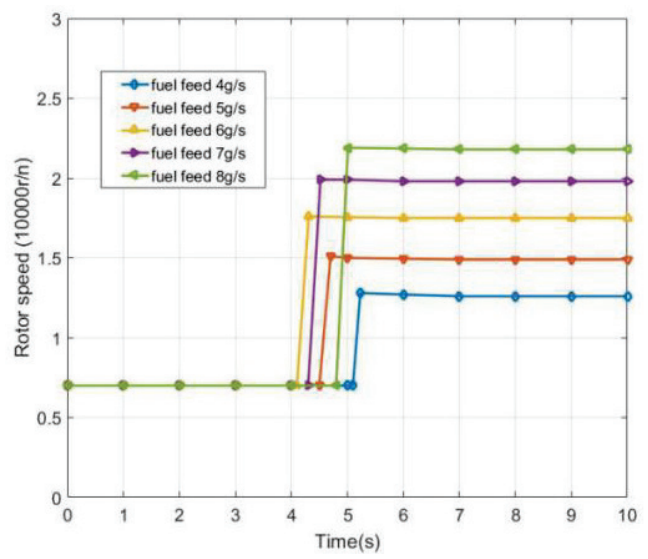

Figure 23 The relationship between starting time and rotor speed under different fuel supply conditions at 7000 starting motor speed

Table 4 Starting time consuming and idling performance of each group

\begin{tabular}{|c|c|c|c|c|}
\hline Test group & $\begin{array}{c}\text { The lowest } \\
\text { starting time } \\
\text { consuming (s) }\end{array}$ & $\begin{array}{c}\text { Idle time } \\
(\mathrm{min})\end{array}$ & $\begin{array}{c}\text { Accidental } \\
\text { parking }\end{array}$ & $\begin{array}{c}\text { Flame out } \\
\text { mode }\end{array}$ \\
\hline $\begin{array}{c}\text { Fuel feed } \\
4 \mathrm{~g} / \mathrm{s}\end{array}$ & 5.23 & 10 & No & $\begin{array}{c}\text { Cut-off fuel } \\
\text { supply }\end{array}$ \\
\hline $\begin{array}{c}\text { Fuel feed } \\
5 \mathrm{~g} / \mathrm{s}\end{array}$ & 4.70 & 10 & No & $\begin{array}{c}\text { Cut-off fuel } \\
\text { supply }\end{array}$ \\
\hline $\begin{array}{c}\text { Fuel feed } \\
6 \mathrm{~g} / \mathrm{s}\end{array}$ & 4.54 & 10 & No & $\begin{array}{c}\text { Cut-off fuel } \\
\text { supply }\end{array}$ \\
\hline $\begin{array}{c}\text { Fuel feed } \\
7 \mathrm{~g} / \mathrm{s}\end{array}$ & 4.52 & 10 & No & $\begin{array}{c}\text { Cut-off fuel } \\
\text { supply }\end{array}$ \\
\hline $\begin{array}{c}\text { Fuel feed } \\
8 \mathrm{~g} / \mathrm{s}\end{array}$ & 5.01 & 10 & No & $\begin{array}{c}\text { Cut-off fuel } \\
\text { supply }\end{array}$ \\
\hline
\end{tabular}

We further examined the ignition reliability. The test results are shown in Tab. 4. It is known from the data in table 4 that this starting method has high reliability and the turbojet runs steadily after starting. It can be conjectured 
that the turbojet will run smoothly and steadily without cutting off the fuel.

After ignition, the rotor speed rises rapidly and exceeds the motor speed, causing the clutch separating with the end of rotor shaft. There was no accidental parking within $10 \mathrm{~min}$ while the engine was in the idle state.

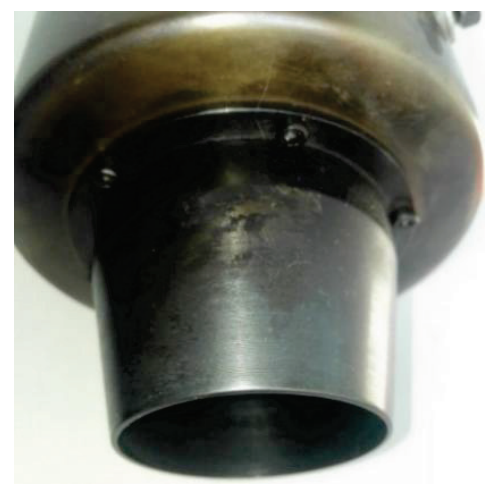

Figure 24 Tail nozzle after combustion

Fig. 24 shows the nozzle color after tests. It can be seen that the tail nozzle and shell obviously have high temperature combustion area. Disassemble the machine and observe the conditions of the combustion chamber, diffuser and bearing seat, as is shown in Fig. 25. Bearing area and the vicinity of the region is clean and without significant carbon deposition.

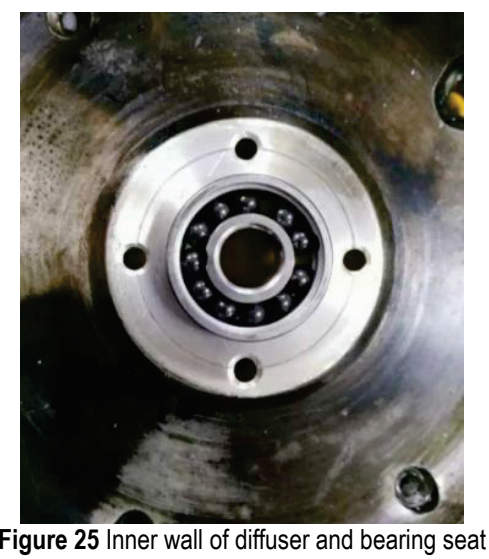

\section{CONCLUSIONS}

In this paper, an ignition system suitable for diesel fuel, which uses motor assisted starting and a silicon nitride ceramic ignitor turbojet engine, has been studied in detail. The feasibility of diesel as a small turbojet fuel is analyzed from the improvement of combustion chamber and evaporator, selection of ignitor installing position and sustainability of fire. Finally, a number of groups of fuel ignition tests were carried out. Limited by the experimental conditions, the test is relatively simple, and idle time is short. And there is no acceleration, durability, high altitude performance, cold resistance ability and other assessment tests. These aspects need to be further studied.

\section{REFERENCES}

[1] Shou, Z. Q. (1981). Calculation of Windmilling Characteristics of Turbojet Engines. ASME Journal of Engineering for Power, 103, 1-12. https://doi.org/10.1115/1.3230697

[2] Morita, M. \& Sasaki, M. (1989). Restart Characteristics of Turbofan Engines. ISABE 89-7127, $9^{\text {th }}, 1200-1206$

[3] Parmington, B. (1922). A Preliminary Investigation into the Feasibility of Using a Small Turbojet to Propel an Expendable Hovering Decoy. ADA256320.

[4] Davison, C. R. \& Birk, A. M. (2004). Set-up and operational experience with a micro-turbine engine for research and education. ASME Paper GT-2004-53377. https://doi.org/10.1115/GT2004-53377

[5] Peng, C. Z., Guo, F. M. et al. (2011). Preliminary exploration of the development of power equipment and technology for cruise missile. Journal of Propulsion Technology, 10, 84-88.

[6] Feng, C. \& Hua, W. (2011). Overview and Prospect of the latest development of cruise missile. Silicon Vally, 01, 1-2.

[7] Kucera, J. (2006). Fort Lauderdale. Future of LAM hangs on tests. Jane's Defence Weekly, 2(22).

[8] Qiu, Q. M. \& Feng, X. P. (2011). Study on the Mechanism of the Diesel Fuel Lubricity. Lubrication Engineering, 12(36), 85-88.

[9] Luo, Y. D., Li, F. X., \& Guo, Y. C. (2015). Investigation of the relationship between diesel fuel lubricity and its constitute. Lubrication Engineering, 02, 97-99.

[10] Nascimento, M. A. R., Lora, E. S., Correa, P. S. P., Andrade, R. V., \& Rendon, M. A. (2006). Biodiesel fuel in diesel micro turbine engine: modeling and experiment evaluation. Energy, 33(2), 233-240. https://doi.org/10.1016/j.energy.2007.07.014

[11] Timko, M. T., Yu, Z., Onasch, T. B., Wong, H. W., \& Miakelye, R. C. (2010). Particulate Emissions of Gas Turbine Engine Combustion of a Fischer-Tropsch Synthetic Fuel. Energy Fuels, 24(11), 5883-5896. https://doi.org/10.1021/ef100727t

[12] Corporan, E., Dewit, M. J., Belovich, V., Pawlik, R., Lynch, A. C. (2007). Emissions Characteristics of a Turbine Engine and Research Combustor Burning a Fischer-Tropsch Jet Fuel. Energy Fuels, 21(5), 2615-2626. https://doi.org/10.1021/ef070015j

[13] Kolesnichenko, Y. I., Lutsenko, V. V., \& Reznik, S. N. (1994). Investigation of ignition conditions and thermally unstable burn in plasma. Fusion Technology, 25(1), 84-94. https://doi.org/10.13182/FST94-A30237

[14] Xie, K. (2018). Effective Ignition Control in Advanced Combustion Engines, PhD Thesis. University of Windsor.

[15] Ballal, D. R. \& Lefebvre, A. H. (1972). A proposed method for calculating film-cooled wall temperatures in gas turbine combustion chambers. ASME paper 72-WA/HT-24.

[16] Chiu, W. S., Shahed, S. M., \& Lyn, W. T. (1976). A Transient Spray Mixing Model for Diesel Combustion. Automotive Engineering Congress \& Exposition, 01, 28-39. https://doi.org/10.4271/760128

[17] Qi, K., Feng, L., Leng, X., Du, B., \& Long, W. (2011). Simulation of quasi-dimensional combustion model for predicting diesel engine performance. Applied Mathematical Modelling, 35(2), 930-940. https://doi.org/10.1016/j.apm.2010.07.047

[18] Lin, Y. Z., Liu, J. et al. (2006). Study on vaporization rate of a mini $\Gamma$-vaporizer under atmospheric pressure condition. Journal of Aerospace Power, 10(21), 843-847.

[19] Huang, Y., Lin, Y. Z. et al. (2009). Combustion and combustor. Beijing, Beihang University press., 09:300-301. 


\section{Contact information:}

\section{Lei QIU}

Key Laboratory of E\&M, Ministry of Education \& Zhejiang Province,

Hangzhou, China

Zhejiang University of Technology, Hangzhou, China

Xi ZENG, Corresponding author

Key Laboratory of E\&M, Ministry of Education \& Zhejiang Province, Hangzhou, China

Zhejiang University of Technology, Hangzhou, China

E-mail: zengxi_zjut@163.com

\section{Shiming J}

Key Laboratory of E\&M, Ministry of Education \& Zhejiang Province,

Hangzhou, China

\section{Fengfei XI}

Key Laboratory of E\&M, Ministry of Education \& Zhejiang Province, Hangzhou, China

\section{Wenbin QIU}

Key Laboratory of E\&M, Ministry of Education \& Zhejiang Province,

Hangzhou, China

\section{Qianqian ZHENG}

Key Laboratory of E\&M, Ministry of Education \& Zhejiang Province, Hangzhou, China 